\title{
nature
}

\section{Science and religion in harmony}

\author{
A spiritual leader with an interest in research has encountered opposition to his plans to speak at a \\ scientific meeting. But he is perfectly entitled to do so.
}

T he Dalai Lama is due to speak at the annual Society for Neuroscience meeting in Washington DC on 12 November, and some neuroscientists don't like it (see Nature 436, 452; 2005). But the Buddhist leader's talk is part of a lecture series that the society is laudably conducting on the science and society — and it should go ahead as planned.

The invitation of the Dalai Lama to the meeting will be interpreted in some quarters as an insult to his nemesis, China. And, citing the oft-repeated refrain that science and religion should be kept separate, some neuroscientists are calling for the lecture to be cancelled.

The critics accuse the Dalai Lama of trying to use the meeting to sell science that they regard as substandard: research on the relationship between meditation and physiological changes in the brain. Even the researchers directly involved in these studies, many of whom are working with the encouragement and support of the Dalai Lama, say that the work is in its early stages.

But the society did not invite the Dalai Lama to speak as a scientist. He will be in Washington to kick off its lecture series on "Dialogues between Neuroscience and Society", in which non-scientists are expected to address "subjects of interest to neuroscientists". The second such lecture will be given by Frank Gehry, the architect who designed the Guggenheim Museum in Bilbao, Spain.

Since Nature first reported on this story three weeks ago, several neuroscientists have written to us criticizing efforts to stop the lecture (see page 912, for example). It seems reasonable to assume that a fair number of the 30,000 delegates expected to attend one of the world's largest scientific meetings will be interested to hear what the Dalai Lama has to say.

The Dalai Lama will not be a complete outsider at the meeting. Through the Colorado-based Mind \& Life Institute, he has already interacted with many reputable neuroscientists. According to the society, he was invited, in part, because "he has already had an influence on the design of experiments of great interest to neuroscientists". As even one opponent of the talk admits: "He has views on controlling negative emotions, which is a legitimate area for neuroscience research in the future." But his lecture does not necessarily constitute an endorsement of his views by the society.

Critics counter that the talk threatens to "entangle the Society for Neuroscience with religious activities". The invitation for the Dalai Lama to speak will give him a chance to sell his religious beliefs in the guise of neuroscience, they claim. Their petition opposing the lecture even draws comparisons between the Dalai Lama, with his belief in reincarnation, and creationists.

But speakers at meetings - non-scientists or scientists - should not be barred on the basis of their religious beliefs. Well-known scientists including Newton have had religious beliefs that many people would disagree with, but these have no bearing on the credibility of their scientific ideas.

Furthermore, in stark contrast with the approach of most religious leaders, the Dalai Lama has tried for many years to encourage empirical research into the claims he makes for the value of meditation. He encourages monks to take part in such experiments. Resulting studies have appeared in respectable scientific journals.

It is true that the invitation could be interpreted as an insult to China. But the manner in which it was issued - by a sci-
"The Dalai Lama encourages monks to take part in experiments. Resulting studies have appeared in respectable scientific journals." entist who was attending a meeting on neuroplasticity at the Dalai Lama's home in India - implies that the neuroscience society harbours no such intent.

It is not unreasonable for the researchers who object to the invitation to protest against it, and to seek to draw attention to the limitations of the Dalai Lama's credentials as a speaker. But now that the point has been made, they should withdraw their threatened boycott of the meeting, and instead raise their issues in the open forum that will follow his talk.

\section{Ratings games}

\section{Researchers have two rare opportunities to influence the ways in which they may be assessed in future.}

1 ow to judge the performance of researchers? Whether one is assessing individuals or their institutions, everyone knows that most citation measures, while alluring, are overly simplistic. Unsurprisingly, most researchers prefer an explicit peer assessment of their work. Yet those same researchers know how time-consuming peer assessment can be.
Against that background, two new efforts to tackle the challenge deserve readers' attention and feedback. One, a citations metric, has the virtue of focusing explicitly on a researcher's cumulative citation achievements. The other, the next UK Research Assessment Exercise, is rooted in a deeper, more qualitative assessment, but feeds into a numerical rating of university departments, the results of which hang around the necks of the less successful for years.

Can there be a fair numerical measure of a researcher's achievements? Jorge Hirsch, a physicist at the University of California, San Diego, believes there can. He has thought about the weaknesses of current attempts to use citations - total counts of citations, averaged or peak citations, or counts of papers above certain citation 
thresholds - and has come up with the ' $h$-index'. This is the highest number of papers that a scientist has written that have each received at least that number of citations; an h-index of 50, for example, means someone has written 50 papers that have each had at least 50 citations. The citations are counted using the tables of citations-todate provided by Thomson ISI of Philadelphia. Within a discipline, the approach generates a scale of comparison that does seem to reflect an individual's achievement thus far, and has already attracted favourable comment (see page 900). The top ten physicists on this scale have $h$ values exceeding 70 , and the top ten biologists have $h$ values of 120 or more, the difference reflecting the citation characteristics of the two fields.

The author placed his proposal on a preprint server last week (www.arxiv.org/abs/physics/0508025), thereby inviting comment before publication. Given the potential for indicators to be seized upon by administrators, readers should examine the suggestion and provide the author with peer assessment.

Whatever its virtues, any citation analysis raises as many questions as it answers and also tracks just one dimension of scientific outputs. Nature has consistently advocated caution in the deployment of the impact factor in particular as a criterion of achievement (an index that Hirsch's h indicator happily ignores). Wisely, the UK Research Assessment Exercise (RAE) has long committed itself to a broader view and the organizers of the next RAE, to take place in 2008, have prohibited assessment panels from judging papers by the impact factors of the journals in which they appeared. What the costs of that will be in panel members' time remains to be seen.

The common approach of the RAE's disciplinary panels is to assess up to four submitted outputs (typically research papers or patents) per researcher, of which a proportion will be assessed in some detail ( $25 \%$ for the biologists, $50 \%$ for the physicists). There will no doubt be something of a challenge in taking into account the fact that a typical publication has several co-authors.

These outputs will sit alongside indicators of the research environment such as funds and infrastructure, and of esteem,
"Given the potential for such indicators to be seized upon by administrators, readers should examine the suggestion and provide the author with some peer assessment." such as personal awards and prestige lectures. The specific indicators to be considered and the weightings applied are now open for public consultation (see www.rae.ac.uk/pubs/2005/04/docs/ consult.doc). Given that the RAE is so influential both nationally and, as a technique, internationally, there is a lot at stake. Stakeholders should express any concerns they may have by the deadline of 19 September.

\section{Climate for progress}

\section{The painstaking US approach to the assessment of climate-change science yields some useful results.}

T he US Climate Change Science Program, which is seeking to produce a comprehensive set of reports on climate change, has been widely criticized as a stalling exercise whose work duplicates that of the Intergovernmental Panel on Climate Change, and whose findings may be prone to political manipulation.

However, the programme yielded some promising outcomes last week, when several participants of a panel it convened published some findings on the apparent discrepancy between the record of warming on the Earth's surface and the change experienced in the troposphere, the lowest level of the atmosphere (see page 896).

The climate-change programme had brought together 22 experts to look into the problem. In the course of five meetings and countless e-mail exchanges, the participants conceded flaws in some of the their earlier analyses and produced new data sets, some of which were published online in Science (doi:10.1126./science1114772; doi:10.1126./science1114867; doi:10.1126./science1115640; 2005).

The release of the draft report summarizing the panel's conclusions for public review, which was due in June, is being delayed, however. The delay may reflect the intrinsic difficulty of getting a large committee containing disparate views to agree on a final form of wording. But it seems to fit in with a pattern at the climate-change programme, which was criticized by the Government Accountability Office in April for failing to meet a 2004 deadline for issuing a new national climate-change assessment. Critics also point out that since the programme issued a strategic plan just two years ago, some of the completion dates for the 21 reports that it plans to produce have slipped by several years.

US government officials say that they were too ambitious in setting the original deadlines. But they also admit that some of the panels' work is being delayed by two other factors: the need to comply with recent legislation that makes it extremely difficult to incorporate fresh scientific information into government reports, and the requirement that the climate-change work is approved at the political, as well as the scientific, level.

The programme's director, James Mahoney, argues that the latter process will be managed in a way that will preclude political interference. Once the sci-
"The handling of the loweratmosphere report over the next few months will help to clarify whether the programme really is a serious attempt to grapple with uncertainty in climate-change science." entific authors have agreed their final draft, the report will be posted online for a 45-day period of public comment. Once that closes, the report will be revised again. Only then, in the final step before publication, will it be reviewed by administration officials.

This process will make it hard for the Bush administration to put its own spin on the report's scientific findings - provided that the drafts are published promptly, without political interference, and that the final documents adhere to the spirit of the drafts. The handling of the lower-atmosphere report - the first from the programme's strategic plan - in the next few months will help clarify whether the programme is a serious attempt to grapple with uncertainty in climate-change science, or is merely an exercise in obfuscation. 